Chapter 6

\title{
Parascript, Parasites and Historical Biogeography
}

\author{
Hugo H. Mejía-Madrid \\ Additional information is available at the end of the chapter \\ http://dx.doi.org/10.5772/55459
}

\section{Introduction}

Eventually there may be enough pieces to form a meaningful language which could be called parascript - the language

of parasites which tells of themselves and their hosts both of today and yesteryear (Manter, 1966) [1].

Few biological interactions have deserved so much attention from biologists during the latter part of the $20^{\text {th }}$ century than host-parasite interactions. Parasites seem to throw a special light on the problems of ecology and evolution. Host-parasite interactions should be considered fine-grained biological models through which major changes in ecosystems can be monitored, e.g., global climate change [2,3]. In the following pages I will review as briefly as possible the main pathways that research on the historical biogeography of parasites has traversed ever since the American parasitologist Harold W Manter coined the term that is the subject matter of this chapter, parascript.

The historical biogeography of parasites is the concern of this chapter mainly because this discipline has gathered a great deal of information during the last two decades on both ecological and evolutionary studies that could be of extended use for future generations in order to know what to do with this planet.

In the late $19^{\text {th }}$ century host-parasite interactions were under the scrutiny of evolutionary biologists ever since von Ihering $[4,5,6]$ anticipated that the location of modern host and parasite biotas (he studied helminths and lice) could be evidence of past distributions. That was a time when Darwin's natural selection was under much debate, and host-parasite studies were used as proof of evolutionary change through channelled paths, called orthogenesis, an opposing view to natural selection. Nevertheless, thanks to von Iher- 
ing's anticipated insight continental drift and plate tectonics would become part of the core of recent parascript studies [6].

Klassen [6] and Brooks [7,8] concluded that the history of the impact of parasite studies in evolutionary biology had been significantly outstanding during the first half of the $20^{\text {th }}$ century. During the critical years of debates on the mechanisms of evolution, e.g., selectionism vs. nonselectionist alternatives (end of $19^{\text {th }}$ and first decades of the $20^{\text {th }}$ century), parasites were at the core of such discussions. Yet, the demise of evolutionary studies on parasites occurred after the inception of the Modern Synthesis of Evolution [8], mainly because parasites fell into discredit as dead evolutionary ends, and as degenerate organisms living at the expense of their hosts. As Fahrenholz viewed it [6,8], parasite evolution just mirrored host evolution. So why bother study parasites under an evolutionary perspective?

American parasitologist Harold W Manter kept alive parasite evolutionary studies during the 1940's and through the rest of his life. These studies were mainly historical biogeographic, although he considered that the interplay between ecology and evolution is the language of parasitology. He viewed such studies as bilingual messages that parasites conveyed, one from the ecological realm and one from evolutionary biology. He named this type of studies, parascript. Today we can interpret parascript studies as global research programmes that study parasite ecology and evolutionary biology from the distinct standpoints of microevolution and macroevolution.

Parascript studies were initially explored by helminthologists $[6,7,8,9]$ but unknowingly left out a great deal of information on insect ectoparasites as voiced by Ròzsa [10] (but see [11]). Parascript studies, therefore, should not be restricted to the type of parasite. Parascript studies should encompass all different types of parasites, whether ecto or endoparasitic. Yet, the differences between them help monitor distinct levels of ecosystem structuring. It is probable that helminth parasites have been surveyed more in relation to historical biogeographical research than ectoparasites in general mainly because Professor Manter was a helminthologist. Currently, parascript is the study of parasites that connect the phylogenetic, biogeographical, historical, and ecological realms, where parasites play an important role as 'thermometers' of environmental status and decidedly offer information on geomorphologic changes of the earth's crust, biogeography, and ecological status, where parasites as part of the interactor universe of their hosts can indicate the connections within trophic foodwebs, migrations, colonizations, and in situ speciation. They are an important if not one of the most important components of biomass in coastal ecosystems [12]. In the words of Hoberg and Klassen [9]: "parasites serve as keystones for understanding the history of biotas because of their critical value as phylogenetic, ecological and biogeographic indicators of their host groups."

\section{Objectives}

The aim of this chapter is to succinctly review past and present research on parasite historical biogeography and concludes what shape could take future research. Parasites have lent themselves to phylogenetic, ecological, and biogeographical analyses ever since von Ihering 
maintained that parasites represent conservative lineages and evolve in isolation [4] (now called allopatric speciation). It was Metcalfe $[6,8,13]$ who actually anticipated the necessity of having phylogenies of both hosts and parasites.

Phylogenetic systematics in particular has played a strong guiding role in parasite historical biogeography during the $20^{\text {th }}$ century and well within the present one $[8,14,15]$. Parasite ecology has generally followed a distinct path (but see $[16,17,8]$ ) that is the consequence of the divorce between ecology and historical biogeography $(16,17,18,19]$ but as rich in conclusions as the evolutionary part. The integration of both disciplines has been named 'parascript' and to a considerable extent, is part of historical ecology studies [1]. Parascript studies have generally dealt with the reconstruction of ancient distributions and geological events, so generally parascript studies have been equated with historical biogeography. Today, different 'branches' of historical biogeographical research have expanded into two seemingly different research programmes: event-based historical biogeography and discovery-based historical biogeography ('pattern based' of Ronquist and Sanmartin [20]). Parasite historical biogeography has benefited from both approaches, but mainly from the latter [21].

Historical background notwithstanding, the present review is centered on metadata based on the relative number of studies published on parasites and historical biogeography that generally utilize phylogenies as initial hypotheses of distribution and area delimitation. When taxon cycles are involved in the discussion, I assume both vicariance and dispersal, according to Halas et al. [22].

It is inevitable to ask why, despite the previous work done $[8,15]$, hotly debated, on methods of historical biogeography, parasite biologists insist on reconstructing host-parasite phylogenies first and add as secondary and unchanging information, geographic distribution? The answer offered by historical biogeography cannot be more persuasive, as this chapter unfolds.

\section{Definitions}

Several definitions are necessary when discussing historical biogeography and parascript. Terms have been discussed in several renderings $[7,8,15,16,23]$. It is outside the scope of this chapter to enter such a discussion. Although the most debated terms in evolutionary biology of parasites have revolved around the words 'coevolution' and 'coadaptation' (and its derivatives), these definitions are nearly related to historical biogeographical concepts, especially when 'coevolution' is interpreted as homologous to 'vicariance'. Historical biogeography is the study of the phylogenetic relationships of different taxa and the areas where they currently live in and where they probably were previously distributed. For some authors [24] it is the study of the evolution of areas and their taxa inhabiting them. The point of departure of all these definitions is the fact that earth and biota evolve simultaneously, at least as a starting or null hypothesis. It is better to say that earth and biota can chronologically evolve in parallel because simultaneity could confound the timing of vicariant and dispersal phenomena. 
Vicariance in temporal terms actually recovers only that part of the evolution of earth and biota that occur simultaneously if earth evolution is deemed as the separation of landmasses, major continental blocks, ocean and river basins, and mountain uplifting that leaves a permanent effect on species. These effects can be traced to speciation events and host-switching, or hybridization, among other phenomena. Dispersal under these terms is the movement, idiosyncratic or concerted (as in range expansions or geodispersal) of whole populations or communities of organisms over those earthly barriers already in existence, due to changes in climate or the breakdown of previous barriers.

\section{Methods}

Database information today is a primer for further research. It is desirable that databases are compiled and then published for the rest of colleagues interested in following some lines of research, especially those who are newcomers to a field of study.

Databases consulted for the present chapter included mainly Web of Science ${ }^{\circledR}$ (WS 1899present) because other databases (Current Contents Connect ${ }^{\circledR}$ (1998-present), Biological Abstracts ${ }^{\circledR}$ (1993-present), Zoological Record ${ }^{\circledR}$ (1976-present), and Journal Citation Reports $\left.{ }^{\circledR}\right)$, are integrated to the WS, have a smaller year-span search record, and the records found in them approximate but are not as complete as those of WS.

I followed in the lead of Poulin and Forbes [25] on the web-based research they employed on host-parasite interactions. The database was developed as a result of the current objective experience that is contained in the literature and research programmes that exploit to its full extent the parascript concept, as defined by Manter [1], and further developed by Brooks and McLennan [8], Hoberg and Klassen [9] and Hoberg et al. [26], among others and in posterior publications by themselves and other researchers. Results were then incorporated into the following categories.

\subsection{Database entries}

Entries were included accordingly as: general type of macroparasite, inferred historical biogeographical patterns, time dimension, terrestrial geomorphological features, taxon level analyzed, methods applied to historical biogeography analysis, and number of papers. Entries included word combinations as 'metadata* parasites* historical biogeography', 'parascript* parasites', 'parasites* biogeography', 'parasites* historical biogeography', 'parascript' as a stand-alone, 'parasite* biogeography' and finally 'parasite* historical biogeography'.

\subsubsection{General type of macroparasite}

Helminths, arthropods -three distinct entries were developed, one that included simultaneously ecto and endohelminths, a second that only included ectoparasites such as mites, ticks and lice, and a third one that included other types of arthropod parasites, e.g., Coleoptera, Lepidoptera, Hymenoptera, Crustacea (Copepoda), and so forth. Pests are not included, 
although agricultural studies represent an area where several discoveries on parasite-host interactions have had their point of departure [27].

\subsubsection{Inferred historical biogeographical patterns}

General type of inferred speciation was used as explanation for perceived patterns of historical biogeography. I only grouped all inferred phenomena under two headings - vicariance and dispersal. In the former I considered several names by which vicariance has come down in the literature: coevolution (of parasites/areas), structure of trees not attributable to chance, hostshifts promote speciation $\approx$ vicariance, cospeciation. Dispersal could be recovered from the records as colonization, chance, non-vicariant processes, range expansion, and geodispersal. Whether all of these designations are equivalent or not exactly equivalent to vicariance or dispersal should not concern us here, as the major debates over historical biogeography clearly are between 'vicariancists' and 'dispersalists' with a variety of definitions according to patterns observed [23]. In the case of dispersion there is evidence that it is a phenomenon not due to chance solely but owes its resulting patterns to other simultaneous events in time, or nearly simultaneous events in time such as environmentally promoted range expansion [28]. When the pattern inferred includes both vicariance and dispersal, I included a third entry.

\subsubsection{The time dimension}

Time is another entry that should be considered $[29,20]$. Needless to say, time is of central importance in historical biogeographical studies [8]. Yet only in later papers time has become more explicit a variable, and not just a framework, as molecular clocks have entered the arena of historical biogeography through phylogeography [26,30-35].

I recorded entries according to the The Beringian Coevolution Project (BCP, [26]) publications that have a clear use of the terms "deep-time" and "shallow-time". Therefore, I recorded deep time as $>1 \times 10^{6}$ years and shallow time as $<1 \times 10^{6}$ years. As many authors seem to combine in their researches explanations that include both age groupings, -in recent papers there seems to be an increase in the use of molecular clock data and phylogeography- I added the category deep/shallow time.

\subsubsection{Terrestrial geomorphological features}

The terrestrial geomorphological features by scale were included in the analysis according to the hierarchical classification of Baker [36]. Authors hardly mention any of these features. The data were entered according to Table 1 but deliberately left out most of those areas that are not mentioned. Area delimitation is still a problem in historical biogeography. No two authors could really agree as to what an area is actually in historical biogeographical studies. 'General areas' is a term often found in the earlier literature on historical biogeography. The first attempts in parasite historical biogeography (summarized in [8]) clearly used drifting continental masses through time, which represents apparently unequivocal designation to discrete areas. Yet, when other geomorphological features are analyzed, authors have resorted to ocean basins, river basins, intermontane geological features, subcontinental regions or vague 
geographical references, like 'eastern' or 'western' areas. There should be an explicit hierarchical usage of these areas for historical biogeographical phenomena operate at different geographical and time scales. Other authors prefer to substitute areas with events [37].

\begin{tabular}{|c|c|c|c|}
\hline Order & $\begin{array}{l}\text { Approximate } \\
\text { Spatial Scale }\left(\mathrm{km}^{2}\right)\end{array}$ & Characteristic Units (with examples) & $\begin{array}{l}\text { Approximate Time } \\
\text { Scale of } \\
\text { Persistence (years) }\end{array}$ \\
\hline 1 & $10^{7}$ & Continents, ocean basins & $10^{8}-10^{9}$ \\
\hline 2 & $10^{5}-10^{6}$ & $\begin{array}{l}\text { Physiographic provinces, shields, depositional plains, } \\
\text { continental-scale river drainage basins (e.g., Amazon, } \\
\text { Mississippi Rivers, Danube, Rio Grande) }\end{array}$ & $10^{8}$ \\
\hline 3 & $10^{4}$ & $\begin{array}{l}\text { Medium-scale tectonic units (sedimentary basins, mountain } \\
\text { massifs, domal uplifts }\end{array}$ & $10^{7}-10^{8}$ \\
\hline 4 & $10^{2}$ & $\begin{array}{l}\text { Smaller tectonic units (fault blocks, volcanoes, troughs, } \\
\text { sedimentary sub-basins, individual mountain zones) }\end{array}$ & $10^{7}$ \\
\hline 5 & $10-10^{2}$ & $\begin{array}{l}\text { Large-scale erosional/depositional units (deltas, major } \\
\text { valleys, piedmonts) }\end{array}$ & $10^{6}$ \\
\hline 6 & $10^{-1}-10$ & $\begin{array}{l}\text { Medium-scale erosional/depositional units or landforms } \\
\text { (floodplains, alluvial fans, moraines, smaller valleys and } \\
\text { canyons) }\end{array}$ & $10^{5}-10^{6}$ \\
\hline 7 & $10^{-2}$ & $\begin{array}{l}\text { Small-scale erosional/depositional units or landforms } \\
\text { (ridges, terraces, and dunes) }\end{array}$ & $10^{4}-10^{5}$ \\
\hline 8 & $10^{-4}$ & $\begin{array}{l}\text { Larger geomorphic process units (hillslopes, sections of } \\
\text { stream channels) }\end{array}$ & $10^{3}$ \\
\hline 9 & $10^{-5}$ & $\begin{array}{l}\text { Medium-scale geomorphic process units (pools and riffles, } \\
\text { river bars, solution pits) }\end{array}$ & $10^{2}$ \\
\hline 10 & $10^{-8}$ & $\begin{array}{l}\text { Microscale geomorphic process units (fluvial and eolian } \\
\text { ripples, glacial striations) }\end{array}$ & $10^{-1}-10^{4}$ \\
\hline
\end{tabular}

Table 1. Classification of Terrestrial Geomorphological Features by Scale. Modified from Baker [36] (http:// disc.sci.gsfc.nasa.gov/geomorphology/GEO_1/GEO_CHAPTER_1.shtml).

\subsubsection{Taxon level analyzed}

Parasites and hosts have decoupled evolutionary histories $[8,23,38]$ when colonization, hostswitching or failure to speciate concurrently with hosts has occurred. Analyzes involving distinct taxon levels have made it clear that parasites seem to speciate in correlation with a change in their physical conditions [39]. The level at which parasites seem to speciate more frequently is at the family level of hosts, correlated with dispersal [38-40]. A distinction between host and parasite levels involved in historical biogeography is at times explicit in such studies. Parasite taxon and host level were recorded as: $1=$ species (or isolate)/genus, $2=$ genera 
(or tribes)/family or subfamily, $3=$ family/order, $4=$ order/class, and $5=$ multiparasite assemblages. When families belonged to the same order, order level was entered; when families corresponded to different orders, multiparasite assemblage was entered instead. I recorded intermediate hierarchical taxon levels as the immediate level above.

\subsubsection{Methods applied to historical biogeography analysis}

Not all methods were incorporated in the analysis, but only those that have been most widely used $[20,41]$.

Panbiogeography is not considered here a historical biogeographic method for it does not consider the time dimension. Interesting research on panbiogeographic tracks of helminth parasites have been published, especially for central Mexico [42,43]. Nevertheless, it is considered here that historical biogeography should begin with phylogenetic reconstructions, where the time dimension is implicitly or explicitly incorporated into such explanations. Parsimony analysis of endemisms (PAE) papers were not considered as well, as PAE is a nonhistorical method. PAE relies on current distribution information of organisms, as it analyzes areas of endemism rather than phylogenetic frameworks of the groups studied rendering it unsuitable as a method of historical biogeography [44].

Separate entries for method employed in historical biogeographical inference were incorparated into the analysis. The combinations of words for generating these data were: Topic $=($ PARASITES $*$ TREEMAP); (PARASITES* BROOKS PARSIMONY ANALYSIS* HISTORICAL BIOGEOGRAPHY), (PARASITES* PARSIMONY* ANALYSIS* FOR COMPARING TREES* PACT* HISTORICAL BIOGEOGRAPHY) (PARASITES* DISPERSAL* VICARIANCE* ANALYSIS* HISTORICAL BIOGEOGRAPHY).

When explanation for a pattern is referred to a previous work by the same author it is considered as extending her/his hypotheses to works examined.

\subsubsection{Number of papers}

The number of papers based on the indicated word combinations was recovered as well as the number of citations per year. I justify this part because it is interesting how the number of publications on historical biogeography of parasites, especially eukaryotes, has fluctuated since the early 1980's. The number of citations was taken into account as a measure of how many times published works have been used among researchers of historical biogeography of parasites.

\section{Results}

The analysis of the database herein presented comprises mainly metazoan parasites of vertebrates, because most of the work on historical biogeography of parasites comes from these phyla. To my knowledge, no one has attempted a complete metanalysis of the works published 
on the historical biogeography of parasites from its beginnings to this time. The following pretends to be a brief account of the data base search undertaken.

No entries for 'metadata* parasites* historical biogeography' were found. This means that there are no metadata analyses of the historical biogeography of parasites. When the words 'parascript* parasites' was entered only 2 entries were recovered in all databases mentioned above, i.e., Brooks and McLennan's [8] book on parascript and Nadler's [45] review in Science. Nevertheless, what is probably the only attempt of reviewing the data on marine parasites from a historical biogeographical standpoint was published nearly 10 years ago [9]. Therefore, more than 20 searches were made by combining 'parasites* biogeography', 'parasites* historical biogeography', 'parascript', among others. The entries 'parasite* biogeography' gave 2677 records, while narrowing to 'parasite* historical biogeography' gave 209 records in an early search (136 in a later one, the origin of that difference could not be assessed). Most of the latter records were contained in the former and because the former did not contain additional information on historical biogeography, I chose the latter 209 records for a metadata analysis.

From the initial 209 entries recovered from the WS, 205 qualified initially for historical biogeography and parasites. When research was narrowed to those papers that concluded with historical biogeography + parasites results, only 75 papers that explicitly report results on the historical biogeography of parasites could be detected. Among these papers blood parasites [46,47,48], plant parasites, mistletoes in South America [49], and fungi [50] are included because it seems that there is a growing interest in historical biogeographical research in non-metazoan eukaryotes that have been used as tags for migratory vertebrates.

Despite the importance of parasites and the consequences of parasitism in modern times, as exemplified by the appearance of emerging infectious diseases [51], the evidence of the interplay between taxon pulses and ecological fitting [28] in the structuring of host-parasite communities in the Holarctic region (and purportedly in other regions of the globe) and its restructuring derived from climatic cycling and current climatic change [26], it is surprising that only circa 200 entries with the words ' parasite historical biogeography' could be recovered. It is evident that a certain number of published works that do not include, happen to mention, or were careful not to mention these words have been excluded from the aforementioned database. For example, Brooks and McLennan's $[8,15,16]$ and references therein] works are not included, when they actually contain the words 'historical biogeography' and 'parasites' repeatedly. Not a single paper of Nieberding and Morand [30-34] is ever mentioned, or the recent book edited by Morand and Krasnov [35] on the biogeography of parasites.

\subsection{General type of macroparasite}

Metadata analysis of historical biogeographical studies of host/parasite/area (Figure 1) indicates that helminth phyla have been the most studied group and within these helminths of freshwater and marine fish, mammals, and birds of the Holartic region [26,30-34], followed afar by bird and mammal ectoparasites (lice and ticks) from northern latitudes, as well [11,23]. A similar situation was recorded 10 years ago from marine parasite historical biogeography [9, Table 1] where 68 works are recorded, among those 51 dealt with helminths (those authors 
had made clear they centered their analysis on these phyla) and 8 with arthropods, plus 8 theoretical works (20 up to 2012). Researchers on arthropod ectoparasites such as lice and ticks seem to have preferred to study host-parasite coevolution rather than their historical biogeography $[23,41]$ though paradoxically some of the first attempts at tracking historical biogeographical patterns used lice as tags for historical biogeography [13].

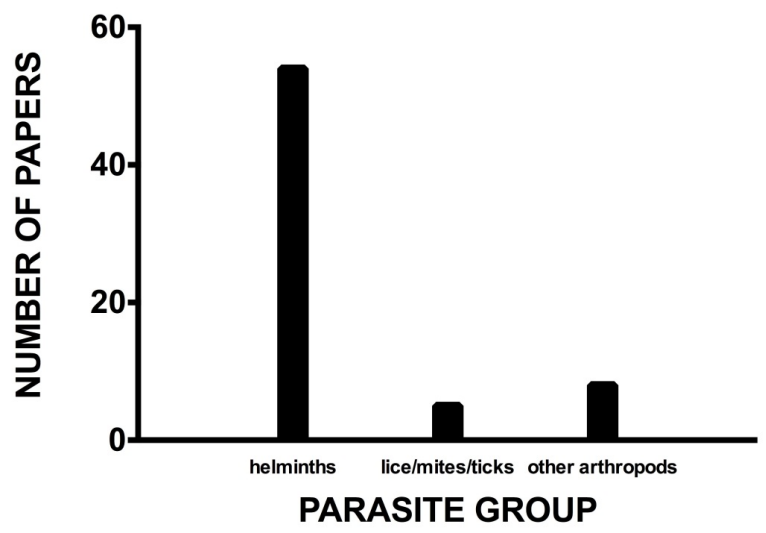

Figure 1. Metadata analysis of parasite historical biogeography. Parasites groups* and papers referring to their historical biogeography. Source of data: Web of Science ${ }^{\circledast}$ (1899-present). * virus, fungi or protozoans not included

\subsection{General type of inferred pattern of historical biogeography}

A significant conclusion of these analyses (Figure 2) is that $15 \%$ of the papers analyzed have recorded patterns of historical biogeography of parasites as vicariant phenomena that involve speciation (coevolution) whereas dispersal events, or host-switching events account for $45 \%$. Papers that mention both vicariance and dispersal account for $40 \%$, a figure near to that of papers that explain pattern with dispersal. If combined, $39 \%$ of papers favour vicariance as an explanation and 61\% dispersal. Dispersion and related phenomena are favored in parasite historical biogeography as the explanation for modern and historical patterns of parasite distribution across and within continents. Differences in the relative occurrence of one or the other phenomenon rely on methods used. Generally, works that employ a priori considerations of parasite evolution and use vicariance as a constraint, recover vicariant patterns, as in the initial versions of TreeMap [23,52]. When no hypothetical considerations are entertained a priori, multiple instances of vicariance and dispersal are recovered [53] for multiple lineages of both parasites and hosts [54]. The consequences of this are manifold but at least a couple can be identified. Parasites tend to disperse from host taxon to host taxon without changing their morphology (but can modify their life cycles), i.e., they are resource trackers [55]. The other consequence relevant to historical biogeography is that a limited number of species of parasites will disperse into large areas invading new hosts and causing pandemics or even 
epidemics [51] and probably leave significant and discoverable tracks in geologic time due to coupled phenomena related to range expansion with little morphological change [55].

Brooks and McLennan $[8,15]$ were the first to suggest that parasites exhibit stronger historical associations "with the areas in which they evolved and lived than with the particular species of hosts they inhabit" [13]. Such statement has been confirmed by the empirical data recovered by parascript studies. Metadata analysis herein included reinforces this view, where mention of a weak cophylogenetic signal is common in these papers. A similar conclusion had already been reached by Manter [56], under a different approach, when comparing helminth faunas of marine fish, although he added a second explanation, namely, that parasites lag behind their hosts in evolutionary time. The consequences of such a discovery has far-reaching implications in the management of large areas of the globe related to human health, livestock, agriculture, migrations, and climatic change.

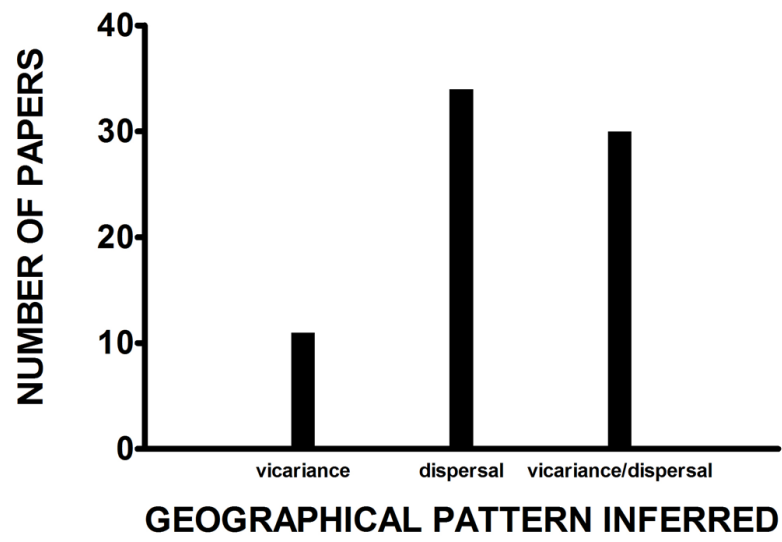

Figure 2. Geographical pattern. Source of data: Web of Science ${ }^{\circledast}$ (1899-present).

This has several implications for the present and future of parascript studies. First, it seems unreliable to ascertain that host/parasite relationships, in a historical perspective, correspond to what has been formerly called parasite specificity. It is now understood that parasites do not track host species, but tend to track host resources that can be represented across different taxa and therefore, are plesiomorphic. It is humans who define host taxa, not parasites [15]. A parasite-centered point of view would be that of "what hosts suits me is what host is my feeding site".

\subsection{The time dimension}

Previous analyses [9] and the one included in this chapter, reflect a deep concern of researchers of historical biogeography for deep time and deep time combined with shallow time (Figure 3). This is actually the case when an increase in works of phylogeography is recorded. Nevertheless, the WS database includes few of these. Major works on the phylgoeography and 
comparative phylogeography of parasites and hosts include explanations on recent (shallow) and ancient (deep) biogeographical phenomena [26, 30-34,57]. Now there is a whole new universe of research where there is growing room for inferring simultaneity of speciation of parasites, hosts, and historical divergence or dispersal into new areas. There have been serious statistical analyses involving simultaneity of divergence [58] in free living organisms, but still not enough on parasites. This is reflected in parascript studies in that most of the cladograms of parasites and areas published up to this day lack an explicit hypothesis of the timing of historical events $[6,20,28]$. In the case of parasites, a lack of fossil evidence seemingly hampers such a calculation, but the growth of research of molecular clocks for both parasites and hosts might be promising [28]. Speculation enters the arena here when we try to deduct the origin of a parasite clade derived from its probable most ancient host. Some attempts have been made earlier [59] with fossils of hosts as calibration points for parasite clades. Nevertheless, the lack of fossils for the parasite associate will always remain and heavy reliance on what host taxon was the original one adds up to this uncertainty. Despite this fact, hypotheses of the original hosts of several endoparasitic [9,60] and ectoparasitic taxa [54] have been utilized as departing points for assessing the origin of particular parasite clades. Parasite counts of modern clades and the use of appropriate net diversification intervals could give some insight as to the antiquity of some key clades [38].

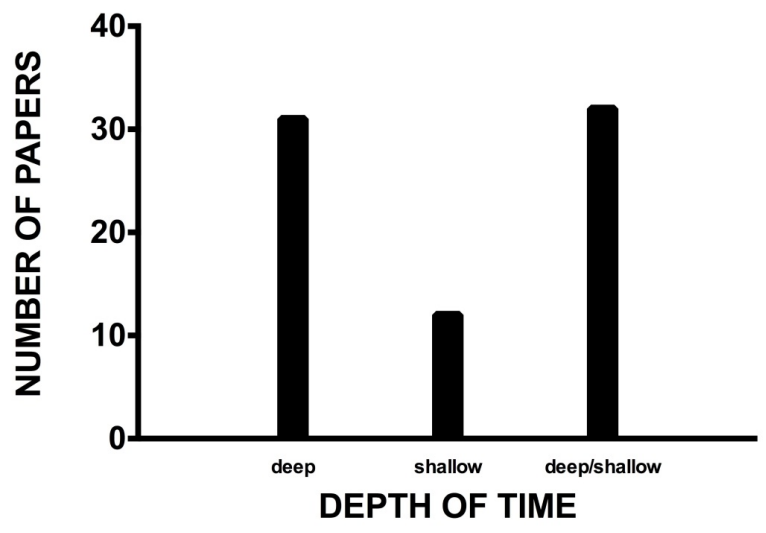

Figure 3. Metadata analysis of parasite historical biogeography. Depth of time. Web of Science ${ }^{\circledR}$ (1899-present).

\subsection{Terrestrial geomorphological features}

According to the classification of geomorphological features, historical biogeography parasitologists are deeply concerned with large continental areas in their analyses (Figure 4). As parasites speciate seemingly with geomorphological changes it is hardly surprising that the higher hierarchical levels of parasite/area were considered as the first targets of historical biogeography. The Holarctic regions has been the most intensively studied [26, 30-34,57]. Southern regions of the earth have been less explored; among these, South America and 
Australia have been the most intensively studied, at the drainage level in the former (Amazon and Paraná drainages mainly) [61-64] and at the continental scale in the latter. It is important to note that areas as terminals in phylogenetic analyses are equal or less in numbers if compared to parasite terminals. Despite the quality of works done on the northern areas of this planet, there are still no independent estimates of the histories of areas [65], where geological studies need to be consulted by parasitologists. Nevertheless, during the modern era of parascript studies, there has been a concern for formulating independent area cladograms of e.g., the breakup of Pangea [8]. Despite the fact that molecular studies have increasingly become incroporated into the historical biogeography of parasites, the breakup of Pangea [66] has remained a very good starting point for historical biogeographical studies and a well supported hypothesis of tectonic plate movements. The latter studies will certainly incorporate more information to the point where it will probably be difficult to discover single independent area histories, especially if dispersal or range expansions are being identified as the engine of parasite speciation. Yet, it would be unvaluable information if independent geological information was explicitly incorporated into historical parascript studies [65].

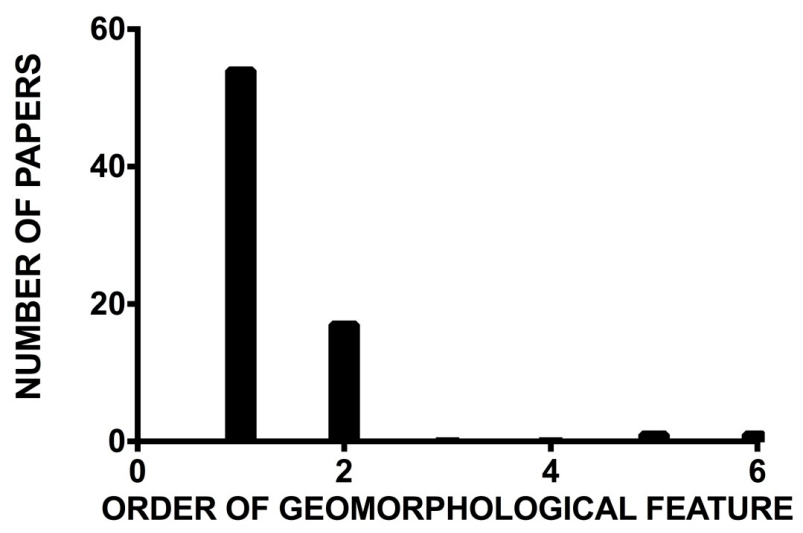

Figure 4. Metadata analysis of parasite historical biogeography. Geolomophological features. Source of data: Web of Science ${ }^{\circledast}$ (1899-present). See Table 1 for descriptions of orders.

\subsection{Taxon level analyzed}

Species level studies seem to be preferred over higher taxonomic levels or multi parasite assemblages (Figure 5). This might represent the difficulties in assessing parasite communities from host assemblages. Additionally, this could reflect that the study of parasite historical biogeography has centered on core species within parasite communities.

Quite a different result was recovered from hosts. A preference for multi host assemblages was recovered in the study of parasite historical biogeography (Figure 6). This could reflect the interest on different host taxa, the availability of different species of hosts or the presence of single parasite species in different hosts. 
Despite the foregoing, a correlation appears between the distinct levels of parasite and host taxa involved in historical biogeographical studies (Figure 7). It is particularly interesting to note that a direct relationship exists between the host taxon level and parasite taxon level. This reflects that as the level of host taxon sampling increases there is an increase in the number of distinct parasite species sampled.

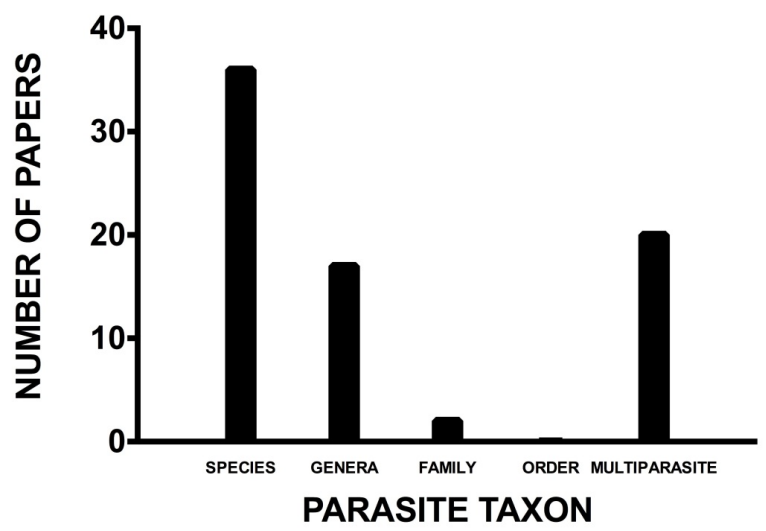

Figure 5. Parasite taxon levels analyzed in historical biogeographical studies.

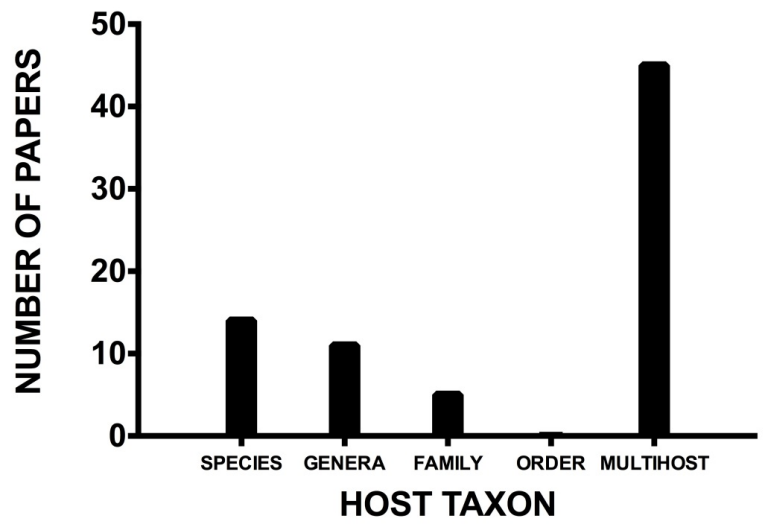

Figure 6. Metadata analysis of parasite historical biogeography. Host taxa levels analyzed in historical biogeographical studies. Source of data: Web of Science ${ }^{\oplus}$ (1899-present). 


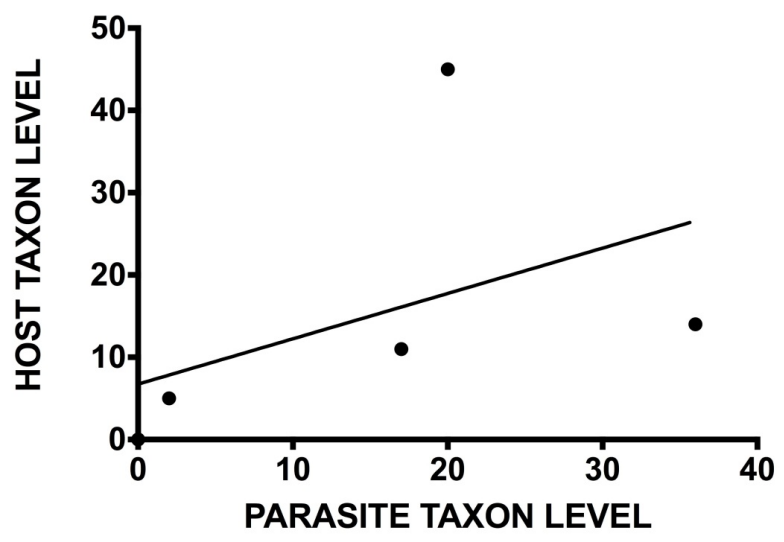

Figure 7. Correlation between host and parasite taxon level. (correlation coefficient $=0.46, t=1, d . f .=6, p>0.01$ ) .

\subsection{Methods employed in historical biogeography of parasites}

Parsimony analysis of host/parasite/area seems to be the dominant optimality criterion for proposing hypotheses of historical biogeography of helminth parasites (Figure 8) while other methods, i.e., component analysis, dispersal-vicariance, among others, have more often been implemented with helminth endoparasites and arthropod ectoparasites phylogenies. Nevertheless, other methods have recently gained acceptance and have been preferred over parsimony and component analyses for the study of historical biogeography [20] but have not been developed in relation to host/parasite/area biogeographic reconstruction. The number of citations amongst the different methods used during the development of parasite historical biogeography have been manifold, but all of them can be grouped mainly in two camps, although there is a growing tendency to use probabilistic methods, probably as a reflection of what is the general trend in phylogenetic reconstruction [20]. Among the parsimony methods and the non-parsimonious methods, I explored the number of citations for at least the four most recurrent used and cited methods: TreeMap [23 and references therein, 52], BPA [8, 15, 16, 67-69], PACT [70-72], and DIVA [73]. The most cited method is DIVA [73]. This could only mean that methods that include both dispersal and vicariance as their working hypothesis have been favored over those that favor maximum cospeciation. DIVA has been equated to secondary BPA [68]. Parsimony methods seemingly took a higher stand during the development of parasite historical biogeography. Nevertheless, statistical-based methods seem to be gaining ground [20] mainly because there is an actual increase in molecular phylogenies (and phylogeographical studies) as compared to recently published morphological phylogenies, although it must be kept in mind that statistical methods can be and have been applied to morphological phylogenies. 


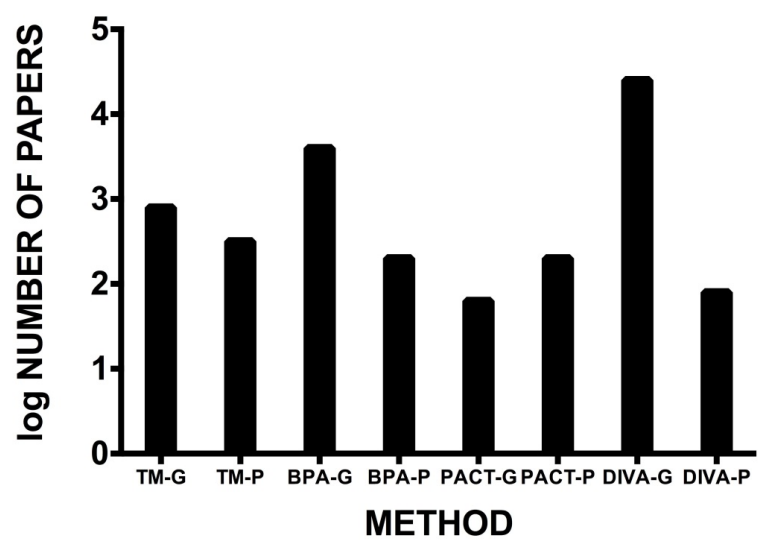

Figure 8. Number of citations per major method used for historical biogeography reconstruction of parasites. Source of data: Web of Science ${ }^{\circledast}$ (1899-present). G- methods used with other groups other than parasites; P-parasite groups.

Analytical methods of patterns and processes in historical biogeography have tended to favor other groups than parasites (Figure 8). DIVA, despite its widespread use, has been very limited in dealing with parasite groups. No wonder, BPA is the method that has been more commonly utilized by parasitologists.

\subsection{Number of papers}

Figures 9 and 10 bring together the number of papers written on the historical biogeography of parasites in general and the number of citations per paper. Number of papers is one and more generally two orders of magnitude below the number of citations per paper. The most cited paper is on the historical biogeography of Drosophila spp. in Africa [74]. The next most cited paper is a work by Rod Page that conflates genes, organisms, and areas without a distinction between hierarchical levels [75]. It is difficult to explain why the number of papers plot is bimodal whereas the citations plot is nearer to an exponential curve. It can be seen that the increase in the use of molecular biology in phylogenetic systematics and phylogeography has increased the number of publications. Interest on this research area has expanded to other regions of the world. As for citation increase, the only other conclusion that can be reached at this stage of research is that historical biogeography of parasites papers have had an enormous impact in areas beyond parasitologists traditional lines of research. 


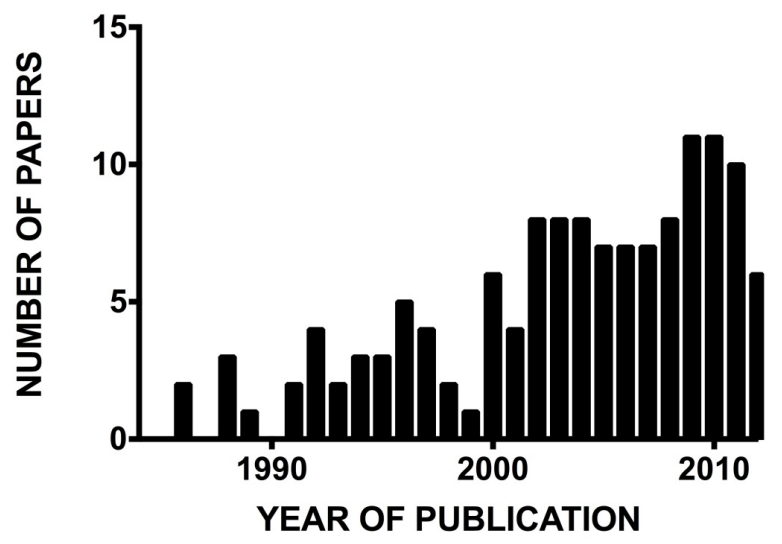

Figure 9. Number of publications on historical biogeography of parasites per year. Source of data: Web of Science ${ }^{\circledR}$ (1899-present).

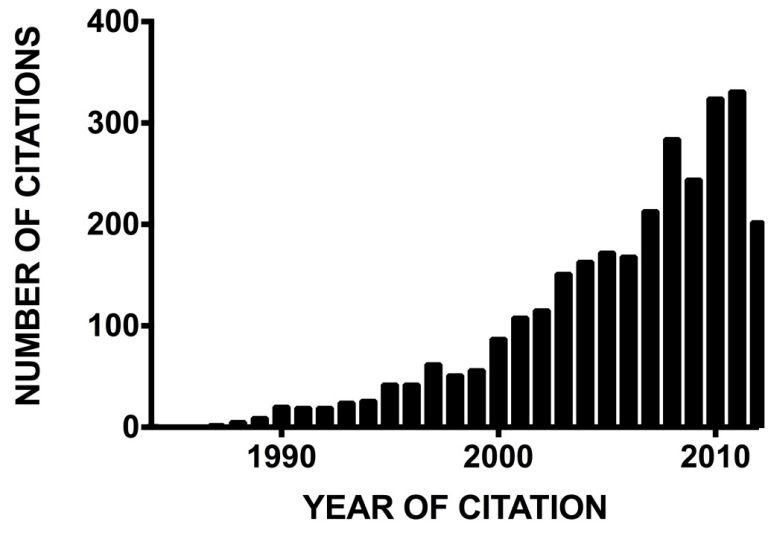

Figure 10. Number of citations on historical biogeography of parasites per year. Source of data: Web of Science ${ }^{\circledR}$ (1899-present).

\section{Discussion}

A metadata analysis of the historical biogeography of parasite studies had never been attempted before. The analyses practiced to the present data were kept as clear as possible. Several shortcomings stemmed from these type of analyses. The most immediate one is related to the combination of several taxa in one paper, e.g., helminths and arthropods. Nevertheless, I found only a single paper that included analysis both on parasitic copepods and endohel- 
minths [76]. Several methods of analyses in a single paper are generally more common. Despite this fact, those papers recovered were substantially TreeMap-oriented or BPA-oriented. PACT is an analysis that has hardly been exploited. Probabilistic analyses are still in their beginnings, so we must see a substantial growth in usage of these methods in the present decade. An indepth analysis of every single paper included in the present chapter would want from space and reading time. Let this brief account of the use of parascript studies, or studies related to the historical biogeographical part be a starting line for further accounts.

The most outstanding problem in modern historical biogeography a decade ago was related to the most approximate method(s) that recovered most of the information contained in parasite/hosts/area phylogenies in order to offer approximate historical biogeographical reconstructions. Nevertheless, numbers indicate there was more concern for reconstructing coevolutionary scenarios than for historical biogeography reconstructions. Under this heading methods have diversified, but today little attention is paid as to what method is used. Instead, the main concerns centers more and more as to the number of genes used to reconstruct phylogenies and then afterwards what the shape of the phylogeny tells us about the biogeography of the taxon or taxa studied. There are substantially excellent reviews on the state of the art in coevolution studies [20]. Yet, there is a need for an equivalent review on historical biogeographical methods that brings together the best ideas from each camp. New computer methods are being implemented, but the assumptions have remained the same. What is notable is that the null hypotheses for historical biogeographical studies depart each day more and more from the original 'coevolutionary' assumption. Parsimony methods have brought about this departure and have influenced all those methods that originally belonged to the 'maximum coevolution' camp. Parsimony methods have moved on and have incorporated cost analysis [41]. Yet some of the methods mentioned in Ronquist and Sanmartin [20] for freeliving organisms have not been explored in host/parasite/area research programmes. Nonparsimony methods, such as ML and Bayesian, have not been incorporated yet into parascript studies but will certainly do in the near future.

\section{Conclusions}

There is little room for doubt that parascript studies, as envisioned by Harold Manter [1], are in the need to enter the application arena. The results obtained by major research programmes, namely the Beringian Coevolutionary Project $(\mathrm{BCP})$, are moving into the direction of a more propositive agenda than ever. This does not mean that data collecting is going to be disregarded. On the contrary, there is today a growing need to increase the number of parasite specimens and hosts as never before.

From the foregoing analysis it seems that the state of the art in parascript studies will head towards a more comprehensive understanding of the biosphere [26]. Regardless of the method employed, it seems that careful and detailed phylogenetic reconstruction, both morphological and molecular, lies at the heart of a sound historical biogeographical reconstruction of events in the earth's past and present. The predictive nature of parascript studies is still being worked 
out, with significative advances stemming from the BCP. One lesson is that methods must lie deep within phylogenetic studies and especially should be fed by the backup and background supported by museum collections of parasites throughout the world [77]. Repositories of parasite specimens cannot be supplanted by any other means of information repository. The very nature of parascript studies depends on well documented specimens that must be deposited in recognized collections around the world. The very curatorial nature of parascript needs a complete overhaul around the most outstanding academic institutions of the world, where most of the information for the historical biogeography of parasites lies for future generations to study the biodiversity on this planet Earth.

\title{
Acknowledgements
}

This work was supported through a SNI grant 43282 from the CONACYT and Facultad de Ciencias, UNAM. Special thanks go to Dr. José G. Palacios-Vargas, head of the Laboratorio de Ecología y Sistemática de Microartrópodos, Facultad de Ciencias, and Dr. Rosaura RuízGutiérrez Director of Facultad de Ciencias, UNAM, for their unvaluable support during the writing of the present work.

\section{Author details}

\author{
Hugo H. Mejía-Madrid
}

Universidad Nacional Autónoma de México/Laboratorio de Ecología y Sistemática de Microartrópodos/Departamento de Ecología y Recursos Naturales, México

\section{References}

[1] Manter HW. The zoogeography of trematodes of marine fishes. Expermiental Parasitology 1966;4 62-86.

[2] Brooks DR, Pérez-Ponce de León G, León-Règagnón V. Enfoques contemporáneos para el estudio de la biodiversidad. México: IBUNAM y Fondo de Cultura Económica; 2001.

[3] Brooks DR, Hoberg EP. Triage for the biosphere: The need and rationale for taxonomic inventories and phylogenetic studies of parasites. Comparative Parasitology 2000;67 1-25.

[4] Von Ihering H. Die Helminthen als Hilfsmittel der zoogeographischen Forshung. Zoologischer Anzeiger 1902;2 42-51. 
[5] Von Ihering H. On the Ancient Relations between New Zealand and South America. Transactions and Proceedings of the New Zealand Institute 1891;24 431-445.

[6] Klassen GJ. Coevolution: A history of the macroevolutionary approach to studying host-parasite associations. Journal of Parasitology 1992;78(4) 573-587.

[7] Brooks DR. Testing the context and extent of host-parasite coevolution. Systematic Zoology 1979;28, 299-307.

[8] Brooks DR, McLennan DA. Parascript. Parasites and the language of evolution. Washington and London: Smithsonian Institution Press; 1993.

[9] Hoberg EP, Klassen GJ. Revealing the faunal tapestry: co-evolution and historical biogeography of hosts and parasites in marine systems. Parasitology 2002;12 S3-S22.

[10] Ròzsa L. Speciation patterns of ectoparasites and "straggling" lice. International Journal for Parasitology 1993;23(7) 859-864.

[11] Hoberg EP, Brooks DR, Siegel-Causey D. Chapter 11. Host-parasite cospeciation: History, principles, and prospects. In: Clayton D H, Moore J. (eds.) Host-parasite evolution: General principles and avian models. U.K.: Oxford University Press, Oxford; 1997. p212-235.

[12] Kuris AM, Hechinger RF, Shaw JC. et al. Ecosystem energetic implications of parasite and free-living biomass in three estuaries. Nature 2008;454 515-518.

[13] Metcalf MM. Parasites and the aid they give in problems of taxonomy, geographical distribution, and paleogeography. Smithsonian Miscellaneous Collections 1929;81(8) $1-36$.

[14] Henning W. Phylogenetic Systematics. USA: Chicago University Press; 1966.

[15] Brooks DR, McLennan DA.The Nature of Diversity: An Evolutionary Voyage of Discovery.USA: University of Chicago Press; 2002.

[16] Brooks DR, McLennan DA. Phylogeny, Ecology and Behavior. A research program in compararive biology. USA: University of Chicago Press; 1991.

[17] Brooks DR. Historical Ecology: A new approach to studying the evolution of ecological associations. Annals of the Missouri Botanical Garden 1985;72(4) 660-680.

[18] Poulin R. Evolutionary Ecology of Parasites. Second Edition. USA: Princeton University Press; 2006.

[19] Wiens JJ, Donoghue MJ. Historical biogeography, ecology and species richness. Trends in Ecology and Evolution 2004;19(12) 639-644.

[20] Ronquist F, Sanmartin I. Phylogenetic Methods in Biogeography. Annual Review of Ecology, Evolution, and Systematics 2011;42 441-64. 
[21] Brooks DR, McLennan DA. A comparison of a discovery-based and an event-based method of historical biogeography. Journal of Biogeography 2001;28(6) 757-767.

[22] Halas D, Zamparo D, Brooks DR. 2005. A historical biogeographical protocol for studying biotic diversification by taxon pulses.Journal of Biogeography 2005;32(2) 249-260.

[23] Page RDM. (ed.) Tangled trees: phylogeny, and coevolution. USA: University of Chicago Press, Chicago; 2003.

[24] Platnick NI, Nelson G. A method of analysis for historical biogeography. Systematic Zoology 1978;27 1-16.

[25] Poulin R, Forbes MR. Meta-analysis and research on host-parasite interactions: past and future. Evolutionary Ecology 2012;26 1169-1185.

[26] Hoberg EP, Galbreath KE, Cook JA, Kutz SJ, Polley L. Chapter 1. Northern Host-Parasite Assemblages: History and Biogeography on the Borderlands of Episodic Climate and Environmental Transition. In: Rollinson D, Hay SI. Advances in Parasitology UK: Elsevier Limited; 79, 2012. p1-97.

[27] Price PW. Evolutionary Biology of Parasites. USA: Princeton University Press; 1980.

[28] Hoberg EP, Brooks DR.Chapter 1: Beyond vicariance: integrating taxon pulses, ecological fitting, and oscillation in evolution and historical biogeography In: Morand S, Krasnov BR (eds.) The Biogeography of Host-Parasite Interactions. U.K.: Oxford University Press, Oxford; 2010. p7-20.

[29] Donoghue MJ, Moore BR.Toward an integrative historical biogeography. Integrative Comparative Biology 2003;43 261-270.

[30] Nieberding C, Morand S, Libois R, Michaux J. A parasite reveals cryptic phylogeographical history of its host. Proceedings of the Royal Society London B 2004;271 2559-68.

[31] Nieberding C, Morand S, Douady CJ, Libois R, Michaux J. Phylogeography of a nematode (Heligmosomoides polygyrus) in the western Palearctic region: Persistence of northern cryptic populations during ice ages? Molecular Ecology 2005;14:765-779.

[32] Morand S, Krasnov BR, Poulin R (eds.) Micromammals and Macroparasites. From Evolutionary Ecology to Management. Tokyo Berlin Heidelberg New York: SpringerVerlag; 2006.

[33] Nieberding CM, Morand S. Chapter 15. Comparative phylogeography: The use of parasites for insights into host history. In: Morand S, Krasnov BR, Poulin R (eds.) Micromammals and Macroparasites. From Evolutionary Ecology to Management. Tokyo Berlin Heidelberg New York: Springer-Verlag; 2006. p277-293. 
[34] Nieberding C, Morand S, Libois R, Michaux JR. Parasites and the island syndrome: the colonization of the western Mediterranean islands by Heligmosomoides polygyrus (Dujardin, 1845). Journal of Biogeography 2006;33(7) 1212-1222.

[35] Morand S, Krasnov BR (eds.) The Biogeography of Host-Parasite Interactions. UK: Oxford University Press; 2010.

[36] Baker VR. Introduction: Regional landforms analysis. In: Short, NM, Blair, RW, Jr. (eds.) Geomorphology from Space. A global overview of regional Landforms. USA: NASA; 1986. Available from http://disc.sci.gsfc.nasa.gov/geomorphology/GEO_1/ GEO_CHAPTER_1.shtml (accessed 17 September 2012).

[37] Hovenkamp P. Vicariance events, not areas, should be used in biogeographical analysis. Cladistics 1997;13 67-79.

[38] Mejía-Madrid HH. Biogeographic Hierarchical Levels and Parasite Speciation. In: Stevens L. (ed.) Global Advances in Biogeography. Rijeka: InTech; 2012. p23-48. Available from: http://www.intechopen.com/books/global-advances-in-biogeography/biogeographic-hierarchical-levels-and-parasite-speciation (accessed 27 August 2012).

[39] Vrba, ES. Mass turnover and heterochrony events in response to physical change. Paleobiology 2005;31(2) 157-174.

[40] Pérez-Ponce de León G, Choudhury A. Biogeography of helminth parasites of freshwater fishes in Mexico: the search for patterns and processes. Journal of Biogeography 2005;32 645-659.

[41] Ronquist F. Parsimony analysis of coevolving species associations. In: Page RDM (ed.) Tangled trees. Phylogeny, cospeciation, and coevolution. USA: The University of Chicago Press; 2003. p22-64.

[42] Aguilar-Aguilar RR, Contreras-Medina R, Salgado-Maldonado G. Parsimony analysis of endemicity (PAE) of Mexican hydrological basins based on helminth parasites of freshwater fishes. Journal of Biogeography 2003;30 1861-1872.

[43] Aguilar-Aguilar RR, Contreras-Medina R, Martínez-Aquino, Salgado-Maldonado G, González-Zamora A. Aplicación del análisis de parsimonia de endemismos (PAE) en los sistemas hidrológicos de México: un ejemplo con helmintos parásitos de peces dulceacuículas. In: Llorente -Bousquets J y Morrone JJ (eds.) Regionalización biogeográfica en Iberoamérica y tópicos afines. México: Comisión Nacional para el Conocimiento y Uso de la Bidoviersidad y Universidad Nacional Autónoma de México; 2003 p227-239.

[44] Brooks DR, van Veller, MGP. Critique of parsimony analysis of endemicity as a method of historical biogeography. Journal of Biogeography 2003;30 819-825.

[45] Nadler SA. Non-Degenerates. Science New Series 1993;261(5123) 927-928. 
[46] Hamilton PB, Cruickshank C, Stevens JR, Teixeira MMG, Mathews F. Parasites reveal movement of bats between the New and Old Worlds. Molecular Phylogenetics and Evolution 2012;6(2) 521-526.

[47] Jenkins T, Thomas GH, Hellgren O, Owens IPF. Migratory behavior of birds affects their coevolutionary relationship with blood parasites. Evolution 2012;66(3) 740-751.

[48] Silva-Iturriza A, Ketmaier V, Tiedemann R. Profound population structure in the Philippine Bulbul Hypsipetes philippinus (Pycnonotidae, Ayes) is not reflected in its Haemoproteus haemosporidian parasites. Infection Genetics and Evolution 2012;12(1) 127- 136.

[49] Amico GC, Nickrent DL. Population structure and phylogeography of the mistletoes Tristerix corymbosus and T. aphyllus (Loranthaceae) using chloroplast DNA sequence variation. American Journal of Botany 2009;96(8) 1571-1580.

[50] Peterson KR, Pfister DH, Bell CD. Cophylogeny and biogeography of the fungal parasite Cyttaria and its host Nothofagus, southern beech. Mycologia 2010;102 (6) 1417-1425.

[51] Brooks DR, Ferrao AL. The historical biogeography of coevolution: emerging infectious diseases are evolutionary accidents waiting to happen. J. Biogeogr. 2005;32 1291-1299.

[52] Page RDM. Parallel phylogenies: reconstructing the history of host-parasite assemblages. Cladistics 1995;10 155-173.

[53] Van Veller MGP, Kornet DJ, Zandee M. A posteriori and a priori methodologies for testing hypotheses of causal processes in vicariance biogeography. Cladistics 2001;7, 248-259.

[54] Smith VS, Ford T, Johnson KP, Johnson PCD, Yoshizawa K, Light, JE. . Multiple lineages of lice pass through the K-Pg boundary. Biology Letters 2011;7(5) 782-785.

[55] Agosta SJ, Janz N, Brooks DR. How specialists can be generalists: resolving the "parasite paradox" and implications for emerging infectious disease. Zoologia 2010;27(2) 151-162.

[56] Manter HW. The zoogeographical affinities of trematodes of South American freshwater fishes. Systematic Zoology 1963;12(2) 45-70.

[57] Choudhury A, Dick TA. Sturgeons and their parasites: Patterns and processes in historical biogeography. Journal of Biogeography, 2001;28 1411-1439.

[58] Hickerson MJ, Stahl EA, Lessios HA. Bayesian Test for simultaneous divergence using approximate computation. Evolution. 2006;60(12) 2435-53.

[59] Verneau O, Du Preez LH, Laurent V, Raharivololoniaina L, Glaw F, Vences M. The double odyssey of Madagascan polystome flatworms leads to new insights on the 
origins of their amphibian hosts. Proceedings of the Royal Society B 2009;276 1575-1583.

[60] Hoberg EP, Jones A, Bray RA. Phylogenetic analysis among the families of the Cyclophyllidea (Eucestoda) based on comparative morphology, with new hypotheses for co-evolution in vertebrates. Systematic Parasitology 1999;42 51-73.

[61] Brooks, DR. Origins, diversification, and historical structure of the helminth fauna inhabiting neotropical freshwater stingrays (Potamotrygonidae). Journal of Parasitology 1992;78(4) 588-595.

[62] Lovejoy NR. Stingrays, Parasites, and Neotropical Biogeography: A closer look at Brooks et al.'s hypotheses concerning the origins of Neotropical freshwater rays (Potamotrygonidae). Systematic Biology 1997;46(1) 218-230.

[63] Boeger WA, Kritsky DC, Pie MR. Context of diversification of the viviparous Gyrodactylidae (Platyhelminthes, Monogenoidea). Zoologica Scripta 2003;32(5) 437-448.

[64] Bandoni SM, Brooks DR. Revision and phylogenetic analysis of the Amphilinidea Poche, 1922 (Platyhelminthes: Cercomeria: Cercomeromorpha). Canadian Journal of Zoology 1987;65, 1110-1128.

[65] Siddall ME, Perkins SL. Brooks Parsimony Analysis: a valiant failure. Cladistics 2003;19 554-564.

[66] Badets M, Whittington I, Lalubin F, Allienne J-F, MaspimbyJ-L, Bentz S, Du Preez LH, Barton D, Hasegawa H, Tandon V, Imkongwapang R, Ohler A, Combes C, Verneau $\mathrm{O}$. Correlating early evolution of parasitic platyhelminths to Gondwana breakup. Systematic Biology 2011;60(6) 762-781.

[67] Brooks DR, vanVeller MGP, McLennan DA. How to do BPA, really. Journal of Biogeography 2001;28 343-358.

[68] Dowling APG. A rigorous test of accuracy between Brooks Parsimony Analysis and TREEMAP, the two most commonly used methods for determining coevolutionary patterns. Cladistics 2002;18 416-435.

[69] Brooks DR, Dowling APG, van Veller MGP, Hoberg EP. Ending a decade of deception: a valiant failure, a not-sovaliant failure, and a success story. Cladistics 2004;20, 32-46.

[70] Wojcicki M, Brooks DR. Escaping the matrix: a new algorithm for phylogenetic comparative studies of co-evolution. Cladistics 2004;20 341-361.

[71] Wojcicki M, Brooks DR. PACT: an efficient and powerful algorithm for generating area cladograms. Journal of Biogeography 2005;32 755-774.

[72] Arias JS, Garzón Orduña IJ, López-Osorio F, Parada Vargas E, Miranda-Esquivel DR. What is PACT really? Cladistics 2008;24 1-12. 
[73] Ronquist F. Dispersal-vicariance analysis: a new approach to the quantification of historical biogeography. Systematic Biology 1997;46 195-203

[74] Lachaise D, Cariou ML, David JR, Lemeunier F, Tsacas L, Ashburner, M. Historical biogeography of the Drosophila-melanogaster species subgroup. Evolutionary Biology 1988;22 159-225.

[75] Page, RDM. Maps between trees and cladistic-analysis of historical associations among genes, organisms, and areas. Systematic Biology 1994;43(1)58-77

[76] Avenant-Oldewage A, Oldewage WH. The occurrence of fish parasites in the Kwando River, Caprivi, Namibia. Madoqua 1993;18(2) 183-185.

[77] Hoberg EP, Pilitt PA, Galbreath KE. Why Museums Matter: A Tale of Pinworms (Oxyuroidea: Heteroxynematidae) Among Pikas (Ochotona princeps and O. collaris) in the American West. Journal of Parasitology 2009;95(2) 490-501. 